\title{
Correction: Márquez-Domínguez, S.; Sørensen, J.D. Fatigue Reliability and Calibration of Fatigue Design Factors for Offshore Wind Turbines. Energies 2012, 5, 1816-1834
}

\section{Sergio Márquez-Domínguez * and John D. Sørensen}

Aalborg University, Sohngaardsholmsvej 57, DK-9000 Aalborg, Denmark; E-Mail: jds@civil.aau.dk

* Author to whom correspondence should be addressed; E-Mail: smd@civil.aau.dk;

Tel.: +45-9940-8575; Fax: +45-9940-8552.

Received: 29 January 2014 / Accepted: 26 February 2014 / Published: 1 April 2014

The authors wish to make the following correction to this paper [1]. On page 1831, the titles of Tables 18 and 19 were incorrect, and should be changed from

Table 18. Required $F D F$ values for minimum cumulative reliability level. SN-curve: "With cathodic protection". Close visual inspection.

\begin{tabular}{cccccc}
\hline $\boldsymbol{\beta}$ /number of inspections & $\mathbf{0}$ & $\mathbf{1}$ & $\mathbf{2}$ & $\mathbf{4}$ & $\mathbf{1 0}$ \\
\hline 2.5 & 3.4 & 2.7 & 2.3 & 1.3 & 1 \\
3.1 & 6.1 & 5.0 & 4.1 & 2.8 & 1 \\
\hline
\end{tabular}

Table 19. Required $F D F$ values for minimum cumulative reliability level. SN-curve: "With cathodic protection". Inspections with the Eddy Current technique.

\begin{tabular}{cccccc}
\hline $\boldsymbol{\beta}$ /number of inspections & $\mathbf{0}$ & $\mathbf{1}$ & $\mathbf{2}$ & $\mathbf{4}$ & $\mathbf{1 0}$ \\
\hline 2.5 & 3.4 & 3.0 & 2.7 & 2.3 & 1 \\
3.1 & 6.1 & 5.3 & 5.0 & 3.6 & 1.3 \\
\hline
\end{tabular}

to the correct versions as follows:

Table 18. Required $F D F$ values for minimum cumulative reliability level. SN-curve: "With cathodic protection". Inspections with the eddy current technique.

\begin{tabular}{cccccc}
\hline $\boldsymbol{\beta}$ /number of inspections & $\mathbf{0}$ & $\mathbf{1}$ & $\mathbf{2}$ & $\mathbf{4}$ & $\mathbf{1 0}$ \\
\hline 2.5 & 3.4 & 2.7 & 2.3 & 1.3 & 1 \\
3.1 & 6.1 & 5.0 & 4.1 & 2.8 & 1 \\
\hline
\end{tabular}


Table 19. Required $F D F$ values for minimum cumulative reliability level. SN-curve: "With cathodic protection". Close visual inspection.

\begin{tabular}{cccccc}
\hline $\boldsymbol{\beta}$ /number of inspections & $\mathbf{0}$ & $\mathbf{1}$ & $\mathbf{2}$ & $\mathbf{4}$ & $\mathbf{1 0}$ \\
\hline 2.5 & 3.4 & 3.0 & 2.7 & 2.3 & 1 \\
3.1 & 6.1 & 5.3 & 5.0 & 3.6 & 1.3 \\
\hline
\end{tabular}

The authors would like to apologize for any inconvenience caused to the readers by this change.

\section{Reference}

1. Márquez-Domínguez, S.; Sørensen, J.D. Fatigue Reliability and Calibration of Fatigue Design Factors for Offshore Wind Turbines. Energies 2012, 5, 1816-1834.

(C) 2014 by the authors; licensee MDPI, Basel, Switzerland. This article is an open access article distributed under the terms and conditions of the Creative Commons Attribution license (http://creativecommons.org/licenses/by/3.0/). 